\title{
Intracanal dressing paste composed by calcium hydroxide, chlorhexidine and zinc oxide for the treatment of immature and mature traumatized teeth
}

\author{
Adriana de Jesus Soares, Thiago Farias Rocha Lima, Juliana Yuri Nagata, \\ Brenda Paula Figueiredo de Almeida Gomes, Alexandre Augusto Zaia, Francisco José de Souza-Filho
}

Universidade Estadual de Campinas - UNICAMP, Piracicaba Dental School, Department of Restorative Dentistry, Area of Endodontics, Piracicaba, SP, Brasi

\begin{abstract}
Aim: To evaluate clinical and radiographic aspects before and after endodontic treatment with an intracanal dressing paste composed of calcium hydroxide, chlorhexidine and zinc oxide in traumatized teeth followed-up for 1 year. Methods: Patients $(n=105)$ treated at the Dental Trauma Service of Piracicaba School of Dentistry, Brazil were enrolled in the study. Two groups of teeth were formed: immature (G1) (n=28) and completely developed teeth (G2) ( $n=174)$. All teeth were endodontically treated and received an intracanal dressing with a paste composed by calcium hydroxide, $2 \%$ chlorhexidine gel and zinc oxide at a 2:1:2 rate. Clinical and radiographic aspects were evaluated initially, monthly and after 1-year. Results: Most of the immature teeth suffered extrusive luxation (39.3\%), whereas intrusive luxation (40.8\%) was more common in completely developed teeth. There was a significant reduction in pain on percussion and mobility $(p=0.0001)$ for immature teeth. Mature teeth showed reduction of spontaneous pain, fistula, mobility and pain on percussion $(p<0.0001)$. Radiographic examination showed decrease in all evaluated parameters for both groups, in addition to stabilization of root resorption. Conclusions: This new intracanal dressing paste for traumatized teeth showed promising results in both immature and completely developed teeth, and may prevent posttraumatic complications.
\end{abstract}

Keywords: calcium hydroxide; dental trauma; treatment.

\section{Introduction}

Received for publication: January 12, 2014 Accepted: March 10, 2014

Correspondence to: Adriana de Jesus Soares Área de Endodontia, Faculdade de Odontologia de Piracicaba, UNICAMP Avenida Limeira, 901, CEP: 13414-018 - Piracicaba, SP, Brasil Phone: +55 $193251-7138$ E-mail: ajsoares.endo@uol.com.br
Dental trauma may cause damage to the pulp and periodontal tissues ${ }^{1}$. Depending on the intensity and type of injury, damage may be reversible or present an unfavorable prognosis for these tissues ${ }^{2}$. Among the dental trauma complications, the most common are pulp necrosis and microbial infection, which may accelerate the root resorption process ${ }^{2-3}$. In order to minimize these complications, endodontic treatment should be performed at an appropriate time to reduce infective and irritant agents.

In dental trauma situations, endodontic treatment involves the use of intracanal dressing between sessions as a complementary factor to eliminate and reduce microorganisms, prevent or stabilize root resorption, induce dentin formation 
and periapical tissue repair ${ }^{4}$. Another factor that may influence endodontic therapy is the stage of root development of the traumatized tooth. Immature teeth present a wide open apex that may favor revascularization and repair of the vascular bundle after trauma. In these teeth the frequency of pulp necrosis is lower $(13.6 \%)$ than in teeth completely closed roots $(63.1 \%)^{3}$.

Despite the more favorable prognosis for immature teeth, the need for endodontic therapy may be a challenge to conventional endodontic treatment. In these situations, some types of treatment have been proposed, including apexification with periodic changes of intracanal dressing, apexification with an apical plug, and more recently pulp revascularization ${ }^{56}$. Apexification is the classic treatment and involves periodic changes of intracanal dressing during a period of 6 to 24 months until a calcified mineralized barrier is formed, allowing apical sealing of the tooth ${ }^{7}$. More recently, pulp revascularization has demonstrated promising results, with root end development in immature teeth with indication for endodontic therapy ${ }^{8-10}$. Nevertheless, there are situations in which pulp revascularization may not be the first choice, considering the need for rehabilitation with intracanal retainers, root resorption and possibility of complications of this little known therapy. Contrasting with the uncertainty about this new treatment, apexification is a well-known and successful procedure with long-term followup studies ${ }^{11}$. Although it is a well-known procedure, apexification also presents some disadvantages, due to the lack of patient cooperation for intracanal dressing changes, long-term weakening of the root considering the hygroscopic and proteolytic properties of calcium hydroxide, increase of fracture risk and pulp space contamination ${ }^{12}$.

Considering the disadvantage of intracanal dressing changes in traumatized teeth, an intracanal dressing paste composed by calcium hydroxide, chlorhexidine and zinc oxide, which does not require periodic changes, has been proposed ${ }^{13-14}$. This paste may be used regardless of the level of root development, and its qualities include low cost, ease-to-use, high radiopacity, no need for periodic replacement and capacity of inducing mineralization ${ }^{13-15}$. In addition, it has been reported that avulsed teeth with unfavorable prognosis may be treated with this paste for long-term periods without dissolution, resulting in periapical lesion repair ${ }^{16}$.

The aim of this study was to evaluate the clinical and radiographic aspects before and after endodontic treatment with an intracanal dressing paste composed by calcium hydroxide, chlorhexidine and zinc oxide in traumatized teeth followed up for 1 year.

\section{Material and methods}

\section{Sample}

One hundred and five patients presenting 202 traumatized teeth were divided in two groups. The first group (G1) comprised patients with immature teeth $(\mathrm{n}=28)$, and the second one (G2) comprised those having teeth with completely developed roots $(n=174)$ (Table 1$)$. All these patients were treated at the Dental Trauma Service of Piracicaba School of Dentistry - UNICAMP, Endodontics Area.

The research was approved by institutional Ethics Committee and the identities of the patients and their legal representatives were kept confidential. Patients received explanations and were informed that both pictures and periapical radiographs would be used for scientific purposes only. The sample was selected by the clinical charts of patients who were attended in regional hospitals and health centers of the neighboring cities, and from the files of the Oral Diagnosis Department, Oral and Maxillofacial Area of Piracicaba School of Dentistry, UNICAMP. After the emergency visit, patients were referred to the local Dental Trauma Service of Piracicaba School of Dentistry, UNICAMP, Endodontics area, and treated by 3 trained endodontic specialists.

Information was collected about age, gender, number of traumatized teeth, trauma date, etiology of trauma and first attendance date. All patients diagnosed with pulp necrosis, periodontal tissue involvement and radiographic signs suggesting root resorption were included in the research. Teeth with inflammatory exudate or severe alveolar bone ridge destruction were excluded from the study. Pulp sensitivity was evaluated by the thermal test, using a mixture of butane at $-50^{\circ} \mathrm{C}$ (Endo-Frost, Roeko, Langenau, Germany), in association with radiographic findings. In teeth with immature root development (Group 1), the pulp sensitivity test was confirmed by the cavity test.

\section{Endodontic Treatment in Groups 1 and 2}

In both immature (G1) and completely developed teeth (G2) cavity access was performed in a similar manner, using \#1014 diamond burs (K.G. Sorensen, Barueri, SP, Brazil) in a high-speed hand piece with copious sterile saline irrigation. Outline shape was completed with \#3082 blunt-end cylindrical diamond burs (K.G. Sorensen). Afterwards, the teeth were isolated with a rubber dam and stabilized with Super Bonder adhesive (Loctite Brasil Ltda., Itapevi, SP, Brazil).

Chemomechanical preparation in immature teeth was

Table 1. Characterization of groups (G1 and G2).

\begin{tabular}{llcccccccc}
\hline Group & Patients & \multicolumn{3}{c}{ Gender } & \multicolumn{3}{c}{ Age } & Teeth \\
\cline { 3 - 8 } & & Male & Female & $<7$ & $\mathbf{7 - 1 4}$ & $\mathbf{1 5 - 2 0}$ & $\mathbf{2 1 - 2 6}$ & $\mathbf{2 6}$ & \\
$\mathbf{1}$ & $23(21.9 \%)$ & 16 & 7 & 5 & 18 & 0 & 0 & 0 & $28(13.9 \%)$ \\
$\mathbf{2}$ & $82(78.1 \%)$ & 57 & 25 & 0 & 42 & 20 & 10 & 10 & $174(86.1 \%)$ \\
\hline Total & $105(100 \%)$ & $73(69.5 \%)$ & $32(30.5 \%)$ & $5(4.8 \%)$ & $60(57.1 \%)$ & $20(19 \%)$ & $10(9.6 \%)$ & $10(9.6 \%)$ & $202(100 \%)$ \\
\hline
\end{tabular}


modified due to the thickness of dentin walls and open apex. Decontamination in the cervical and middle thirds was performed with Gates-glidden burs \#5, 4, 3 and 2 (Dentsply/ Maillefer, Petrópolis, RJ, Brazil). Length determination was performed by radiographic analyses using a K-file (Dentsply/ Maillefer) inserted up to the apical constriction. Next, the apical third was instrumented with K-files (Dentsply/ Maillefer,), \#50 to 80, inserted up to the apical limit. In some cases, it was necessary to use Hedstroem files (Dentsply/ Maillefer), $\# 50$ to 60 , to the same length, for removing pulp debris. All root canals were filled with $2 \%$ chlorhexidine gel during the entire mechanical preparation procedure and were irrigated with sterile saline solution at each file change. At the conclusion of chemomechanical preparation, 17\% EDTA solution was used for $3 \mathrm{~min}$, and a final irrigation by sterile saline solution after this. After aspiration, the root canals were dried with fitted paper points (Konne Indústria e Comércio de Materiais Odontológicos Ltda., Belo Horizonte, MG, Brazil).

Teeth with closed apex (G2) were subjected to the same decontamination protocol, with the difference that root canal length determination was performed using an electronic apex locator (Novapex; Forum Technologies, Rishon-le-Zion, Israel), and instrumentation with smaller diameter files.

\section{Manipulation and insertion of intracanal dressing}

The intracanal dressing paste was prepared using calcium hydroxide (Biodinâmica TM, Ibiporã, PR, Brazil), 2\% chlorhexidine gel (Farmácia de Manipulação Ltda., Itapetininga, SP, Brazil) and zinc oxide (S.S. White Artigos Dentários Ltda., Rio de Janeiro, RJ, Brazil), ata2:1:2 rate. This paste was manipulated to a firm consistency similar to Coltosol (Vigodent S/A Indústria e Comércio, Rio de Janeiro, RJ, Brazil), and was inserted in increments, using mediumand fine-medium-sized vertical condensors (Konne) (Figure 1) in the entire extent of the root canal up to the apical constriction. A control radiograph was performed to verify the apical limit of the intracanal dressing paste. After this, the teeth were sealed with Coltosol (Vigodent S/A Indústria e Comércio), restored with composite resin (Filtek Z350, 3M Dental Products, Saint Paul, MN, USA), and then radiographed (Figures 2 and 3). The patients were followedup for at least one year. Definitive root canal filling with sealer and gutta-percha was performed only in cases where it was observed dissolution of the paste and need for an esthetic restoration with intracanal posts.

\section{Clinical and radiographic evaluation}

Evaluations were made before and after insertion of the intracanal paste. The clinical examination showed presence or absence of spontaneous pain, abscess, fistula, mobility and sensitivity to percussion. The radiographic examination revealed presence or absence of cortical alveolar bone, periodontal ligament thickness, root resorptions (inflammatory and replacement types) and periapical radiolucency. For radiographic analyses, rapid speed periapical films (Kodak, São José dos Campos, SP, Brazil) and radiographic exposure of $55 \mathrm{kVp}$ and $15 \mathrm{~mA}$ for $0.7 \mathrm{~s}$ were used. An intraoral film holder (Indusbello Indústria de Instrumentos Odontológicos Ltda., Londrina, PR, Brazil) was used to standardize and improve the quality of radiographs. The radiographs of Groups 1and 2 were evaluated using a

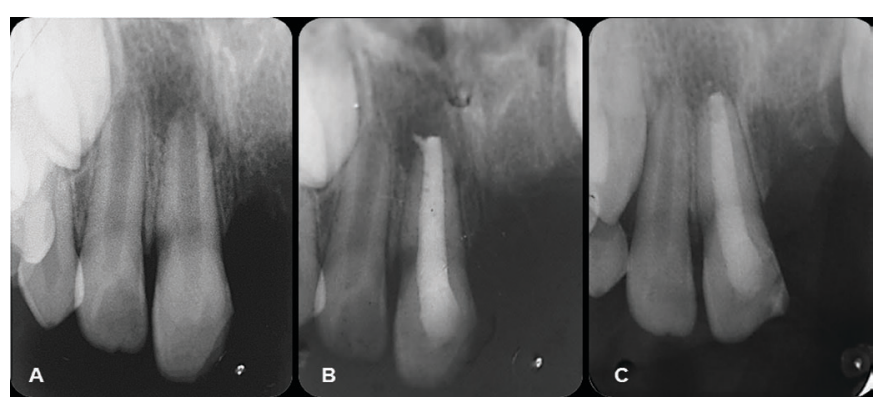

Fig. 1. Preparation of the root filling paste

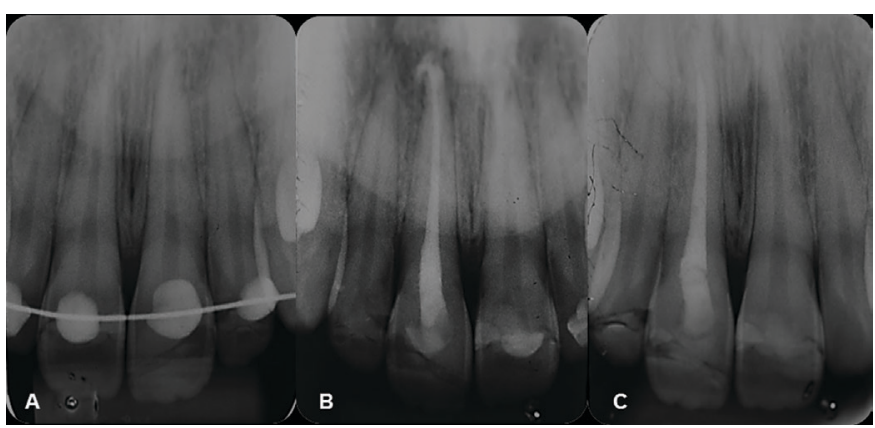

Fig. 2. Immature tooth (Group 1) treated with the root filling paste. (A) Initial radiograph. (B) Treatment with the root filling paste. (C) 12-month follow-up.

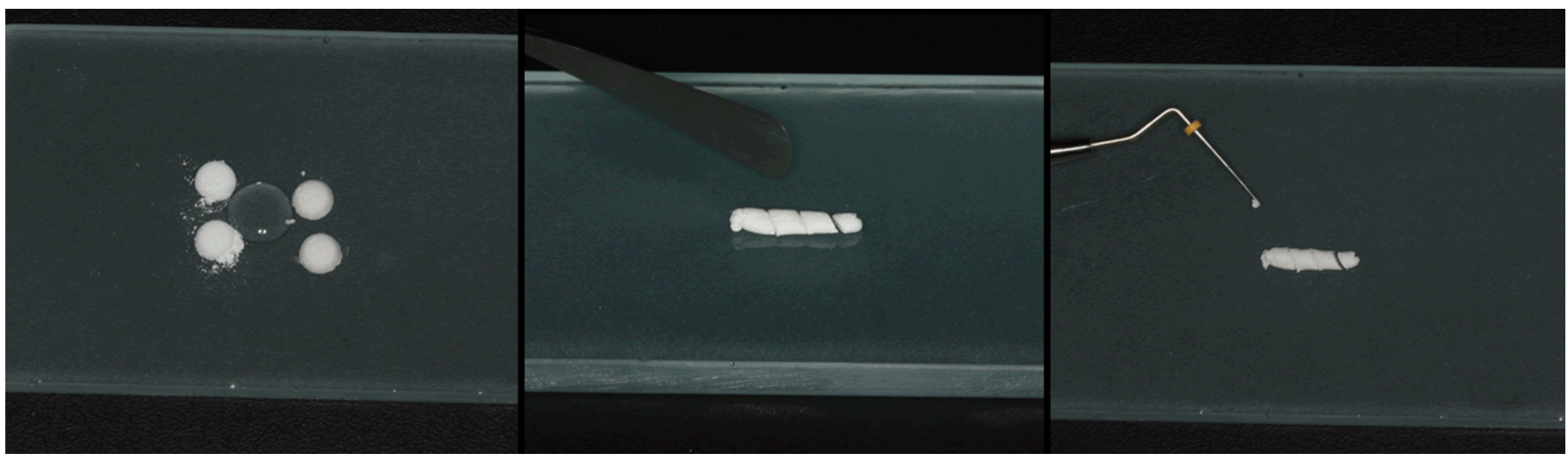

Fig. 3. Mature tooth (Group 2) treated with the root filling paste. (A) Initial radiograph. (B) Treatment with the root filling paste. (C) 12-month follow-up. 
light box (Lumatron; Encor Indústria Fotográfica Ltda, Rio Claro, SP, Brazil), coupled to a lens providing 4 times enlargement.

\section{Statistical analysis}

The results were evaluated in the BioEstat 5.0 program at a level of significance level of $5 \%$. The McNemar test was used to analyze clinical and radiographic parameters before and after insertion of the intracanal paste.

\section{Results}

Groups 1 and 2 were affected by subluxation, extrusive luxation, lateral luxation, intrusive luxation and avulsion. Most of the immature teeth suffered extrusive luxation $(39.3 \%)$, whereas in completely developed teeth, intrusive luxation (40.8\%) was more common (Table 2).

In the clinical evaluation it was observed that in both immature and completely developed teeth there was complete reduction of spontaneous pain, fistula and abscess after the use of the studied intracanal dressing paste(Table 3 ). This decrease was significant for pain on percussion $(p=0.001)$ and mobility $(p=0.0001)$ in immature teeth. For the completely developed teeth, this decrease was statistically

Table 2.Types of dental trauma affecting immature (Group 1) and completely developed teeth (Group 2).

\begin{tabular}{lll}
\hline Dental Trauma & Group 1 & Group 2 \\
Subluxation & $5(17.9 \%)$ & $8(4.7 \%)$ \\
Extrusive Luxation & $11(39.3 \%)$ & $46(26.4 \%)$ \\
Lateral Luxation & $5(17.9 \%)$ & $15(8.6 \%)$ \\
Intrusive Luxation & $1(3.5 \%)$ & $71(40.8 \%)$ \\
Avulsion & $6(21.4 \%)$ & $34(19.5 \%)$ \\
\hline Total & $28(100 \%)$ & $174(100 \%)$ \\
\hline
\end{tabular}

significant for spontaneous pain $(p=0.0001)$, fistula $(\mathrm{p}=0.002)$, mobility $(\mathrm{p}<0.0001)$ and pain on percussion $(\mathrm{p}<0.0001)$.

The radiographic evaluation before and after use of the intracanal dressing paste in immature and completely developed teeth is shown in Table 4.

\section{Discussion}

Dental trauma, depending on its severity, may lead to complications in the pulp and periodontal tissues. Literature reports have shown that intrusive luxation and tooth avulsion are most frequently related to pulp necrosis and root resorptions $(76.2 \%)$, requiring endodontic treatment ${ }^{3}$. In the present study this relationship was also observed for completely developed teeth, since most of the sample presented intrusive luxation $(40.8 \%)$.

Root development must be considered for the treatment to be adopted, since immature teeth present thin dentin walls and open apices, which could make it difficult to achieve appropriate apical sealing and may weaken the root structure. Literature reports have shown promising treatments for these conditions with pulp revascularization and apexification ${ }^{17}$. Revascularization has been studied as an alternative treatment in some cases of incomplete root formation, because it stimulates the thickening and apical closure of immature teeth ${ }^{18-19}$. However, revascularization may present potential clinical and biological complications, such as crown discoloration $^{20}$, development of resistant bacterial strains and allergic reaction to the intracanal medication ${ }^{21}$. Moreover, the mechanism of pulp revascularization, the type of tissue that develops on the root canal walls and the clinical outcome of a long follow-up period are still unclear. Considering these aspects, a more predictable treatment (apexification) was the

Table 3. Clinical evaluation before and after intracanal dressing with filling paste in Groups 1 and 2.

\begin{tabular}{lllllll}
\hline Clinical Aspects & \multicolumn{2}{c}{ Group 1 $(\mathbf{n}=\mathbf{2 8})$} & \multicolumn{3}{c}{ Group 2 $(\mathbf{n}=174)$} \\
Sefore & After & $\mathbf{p}^{*}$ & Before & After & \multicolumn{1}{c}{$\mathbf{p}^{*}$} \\
Spontaneous pain & $1(3.7 \%)$ & $0(0 \%)$ & 1 & $15(8.6 \%)$ & $0(0 \%)$ & 0.0001 \\
Fistula & $3(10.7 \%)$ & $0(0 \%)$ & 0.25 & $10(5.7 \%)$ & $0(0 \%)$ & 0.002 \\
Abscess & $4(14.3 \%)$ & $0(0 \%)$ & 0.125 & $5(2.9 \%)$ & $0(0 \%)$ & 0.0625 \\
Mobility & $12(42.9 \%)$ & $1(3.7 \%)$ & 0.001 & $97(55.7 \%)$ & $15(8.6 \%)$ & $<0.0001$ \\
Pain on percussion & $15(53.6 \%)$ & $1(3.7 \%)$ & 0.0001 & $95(54.6 \%)$ & $7(4 \%)$ & $<0.0001$ \\
\hline
\end{tabular}

* McNemar Test, $p<0.05$

Table 4. Radiographic evaluation observed before and after intracanal dressing with filling paste in immature and completely developed teeth.

\begin{tabular}{lllllll}
\hline Radiographic aspects & \multicolumn{2}{c}{ Group $1(\mathbf{n = 2 8 )}$} & \multicolumn{3}{c}{ Group 2 (n=174) } \\
& Before & After & \multicolumn{1}{c}{$\mathbf{p}^{*}$} & Before & After & $\mathbf{p}^{*}$ \\
Periodontal ligament thickness & $16(57.1 \%)$ & $2(7.1 \%)$ & 0.0001 & $95(54.6 \%)$ & $41(23.6 \%)$ & $<0.0001$ \\
Cortical Alveolar bone & $7(25 \%)$ & $21(75 \%)$ & 0.0001 & 58 & 94 & $<0.0001$ \\
Inflammatory resorption & $3(10.7 \%)$ & $2(7.1 \%)$ & 1 & $42(24.1 \%)$ & $10(5.7 \%)$ & $<0.0001$ \\
Replacement resorption & $3(10.7 \%)$ & $6(21.4 \%)$ & 0.25 & $11(6.3 \%)$ & $49(28.1 \%)$ & $<0.0001$ \\
Periapical radiolucence & $5(17.9 \%)$ & $2(7.1 \%)$ & 0.25 & $70(40.2 \%)$ & $31(17.8 \%)$ & $<0.0001$ \\
\hline${ }^{*}$ McNemar Test, $p<0,05$ & & & & & &
\end{tabular}


treatment of choice in the present study. Apexification usually involves refreshing the calcium hydroxide paste every three months, requiring multiple visits with heavy demands on patients and operators, inevitable clinical costs, and the increased risk of tooth fracture, since the use of calcium hydroxide requires many dressing changes until a calcified barrier isformed ${ }^{12,22}$.

This study demonstrated an alternative to periodic changes of intracanal medication in apexification, using a paste composed by calcium hydroxide, chlorhexidine and zinc oxide. This dressing reduced clinical and radiographic pathological signs, in addition to promoting apical closure even without periodic changes. In previous reports on immature teeth, this medicament was also successfully used in apexification ${ }^{13-15}$. Concurring with the present study, a recent clinical research showed that most of the immature teeth $(74 \%)$ needed only a single application of calcium hydroxide for complete apexification and replacements were required only for teeth presenting displacement and/or sinus tracts $^{23}$.

Endodontic treatment in traumatized teeth with completely developed roots follows the same protocol as for teeth with pulp necrosis due to dental caries. Some authors suggested the need for calcium hydroxide as intracanal medication to prevent complications such as root resorption ${ }^{24}$. The present study also treated these completely formed teeth with intracanal dressing composed by calcium hydroxide, chlorhexidine and zinc oxide. No dissolution of the dressing was observed, which may have acted as a physical barrier preventing contamination of the root canal and periapical region. In addition, it produced a reduction of the clinical and radiographic symptoms and prevented root resorption.

The intracanal dressing paste used in the present study may be used both for immature and completely developed teeth after dental trauma. Technically, it is easy to manipulate, simple to insert with condensers and presents radiopacity, allowing observation of complete filling of the root canal. In addition, it acts as a temporary material and may be more effective than a paste dressing for long periods of follow-up. Considering severe trauma such as tooth avulsion and intrusive luxation that may require long-term follow-up due to high probability of progressive root resorptions, this intracanal dressing paste may be an alternative to gutta-percha obturation. Endodontic filling with gutta-percha and sealer does not dissolve, differently from what occurs with this intracanal dressing paste, since it may dissolve at the same time as it comes into contact with the periapical tissues. This paste also demonstrated antimicrobial properties, and maintained alkaline $\mathrm{pH}$ for one week ${ }^{25}$. It is likely that after some weeks, only zinc oxide was present, since $\mathrm{Ca}(\mathrm{OH})_{2}$ should have undergone complete dissolution ${ }^{14}$. The presence of zinc oxide may have worked as an inert sealing material, preventing contamination, and allowing apical repair and barrier formation in cases of open apices. The absence of a good sealing and the presence of radiographic and clinical symptoms may indicate the need to replace the medication. Further studies should be conducted on the composition, mechanism of action and long term follow-up of cases treated with this intracanal dressing.

More important than the intracanal dressing, is the cleaning of root canal system. Several studies demonstrated that reduction of microorganisms within the root canal allows periapical repair and formation of a calcified tissue barrier in open apex teeth ${ }^{11,17}$. In this study, $2 \%$ chlorhexidine gel was used as auxiliary chemical substance. It was demonstrated that $2 \%$ chlorhexidine gel has excellent antimicrobial activity and is more biocompatible than sodium hypochlorite ${ }^{25}$.

The new intracanal dressing paste for traumatized teeth evaluated in this study showed promising results for both immature and completely developed teeth. All patients presented remission of clinical signs and radiographic reduction or repair of radiolucent lesions and root resorption. The paste, which has calcium hydroxide, chlorhexidine and zinc oxide as main components, may be an alternative for dental trauma cases diagnosed with pulp necrosis, and may prevent post-traumatic complications.

\section{References}

1. Andreasen JO. Pulp and periodontal tissue repair - regeneration or tissue metaplasia after dental trauma. Areview. Dent Traumatol. 2012; 28: 19-24.

2. Al-Jundi SH. Type of treatment, prognosis, and estimation of time spent to manage dental trauma in late presentation cases at a dental teaching hospital: a longitudinal and retrospective study. Dent Traumatol. 2004; 20: 1-5.

3. Hecova H, Tzigkounakis V, Merglova V, Netolicky J. A retrospective study of 889 injured permanent teeth. Dent Traumatol. 2010; 26:466-75.

4. Mohammadi Z, Dummer PM. Properties and applications of calcium hydroxide in endodontics and dental traumatology. Int Endod J. 2011; 44: 697-730.

5. AlAnsary MA, Day PF, Duggal MS, Brunton PA. Interventions for treating traumatized necrotic immature permanent anterior teeth: inducing a calcific barrier \& root strengthening. Dent Traumatol. 2009; 25: 367-79.

6. Turkistani J, Hanno A. Recent trends in the management of dento alveolar traumatic injuries to primary and young permanent teeth. Dent Traumatol. 2011; 27:46-54.

7. Shah N, Logani A, Bhaskar U, Aggarwal V. Efficacy of revascularization to induce apexification/apexogensis in infected, nonvital, immature teeth: a pilot clinical study. J Endod. 2008; 34: 919-25.

8. Cotti E, Mereu M, Lusso D. Regenerative treatment of an immature, traumatized tooth with apical periodontitis: report of a case. J Endod. 2008; 34:611-6.

9. Petrino JA, Boda KK, Shambarger S, Bowles WR, McClanahan SB. Challenges in regenerative endodontics: a case series. J Endod. 2010; 36 : 536-41.

10. Chen MY, Chen KL, Chen CA, Tayebaty F, Rosenberg PA, Lin LM. Responses of immature permanent teeth with infected necrotic pulp tissue and apical periodontitis/abscess to revascularization procedures. Int Endod J. 2012; 45: 294-305.

11. Chala S, Abouqal R, Rida S. Apexification of immature teeth with calcium hydroxide or mineral trioxide aggregate: systematic review and metaanalysis. Oral Surg Oral Med Oral Pathol Oral Radiol Endod. 2011; 112: 36-42.

12. Andreasen JO, Farik B, Munksgaard EC. Long-term calcium hydroxide as a root canal dressing may increase risk of root fracture. Dent Traumatol. 2002; 18: $134-7$.

13. Soares AJ, Lima TFR, Lins FF, Herrera DR, Gomes BPFA, de SouzaFilho FJ. Um nuevo protocolo de medicación intraconducto para dientes com necrosis pulpar y rizogénesis incompleta. Rev Estomatol Herediana. 2011; 21: 145-9. 
14. Soares AJ, Nagata JY, Casarin RCV, Almeida JFA, Gomes BPFA, Zaia $A A$, et al. Apexification by using a new intra-canal medicament: a multidisciplinary case report. Iran Endod J. 2012; 7: 165-70.

15. Soares AJ, Prado M, Lima TFR, Zaia AA, Souza-Filho FJ. The multidisciplinary management of avulsed teeth: a case report. Iran Endod $\mathrm{J}$. 2012; 7: 203-6.

16. Buck CLBP, Soares AJ, Nagata JY, Buck A, Zaia A, Souza-Filho FJ. Evaluation of reimplanted teeth submitted to a new therapeutic protocol. Rev Assoc Paul Cir Dent. 2013; 67: 22-6.

17. Aggarwal V, Miglani S, Singla M. Conventional apexification and revascularization induced maturogenesis of two non-vital, immature teeth in same patient: 24 months follow up of a case. J Conserv Dent. 2012; 15: 68-72.

18. Thibodeau B, Teixeira F, Yamauchi M, Caplan DJ, Trope M. Pulp revascularization of immature dog teeth with apical periodontitis. J Endod. 2007; 33: 680-9.

19. Friedlander LT, Cullinan MP, Love RM. Dental stem cells and their potential role in apexogenesis and apexification. Int Endod J. 2009; 42: 955-62.

20. Kim JH, Kim Y, Shin SJ, Park JW, Jung IY. Tooth discoloration of immature permanent incisor associated with triple antibiotic therapy: a case report. J Endod. 2010; 36: 1086-91.

21. Reynolds K, Johnson JD, Cohenca N. Pulp revascularization of necrotic bilateral bicuspids using a modiûed novel technique to eliminate potential coronal discoloration: a case report. Int Endod J. 2009; 42: 84-92.

22. Rafter M. Apexification: a review. Dent Traumatol. 2005; 21: 1-8.

23. Yassen GH, Chin J, Mohammedsharif AG, Alsoufy SS, Othman SS, Eckert $G$. The effect of frequency of calcium hydroxide dressing change and various pre-and inter-operative factors on the endodontic treatment of traumatized immature permanent incisors. Dent Traumatol. 2012; 28: 296301.

24. Diangelis AJ, Andreasen JO, Ebeleseder KA, Kenny DJ, Trope M, Sigurdsson A, et al. International Association of Dental Traumatology guidelines for the management of traumatic dental injuries: 1 . Fractures and luxations of permanent teeth. Dent Traumatol. 2012; 28: 2-12.

25. de Souza-Filho FJ, Soares Ade J, Vianna ME, Zaia AA, Ferraz CC, Gomes BP. Antimicrobial effect and pH of chlorhexidine gel and calcium hydroxide alone and associated with other materials. Braz Dent J. 2008; 19: 28-33. 